\title{
Production of Ultra Low Nitrogen Ferrochrome and of High Purity Stainless Steel ${ }^{*}$
}

\section{By Hiroyuki KATAYAMA, ,* Shigehiro KIMURA, ${ }^{* *}$ Hiroyuki KAJIOKA** and Michihisa ITOH ${ }^{* * *}$}

\section{Synopsis}

The process of denitriding of low carbon ferrochrome and vacuum melting of high purity stainless steel with denitrided ferrochrome have been investigated.

(1) A pile of ferrochrome in granular form can be denitrided uniformly with $\mathrm{Mg}-\mathrm{MgCl}_{2}$ flux of more than $70 \sim 90 \mathrm{Kg} / \mathrm{t}$ without mechanical stirring to 20 ppm or less.

(2) Under the condition that the terminal nitrogen content of ferrochrome is independent of its size, the influences of temperature, amount of fux and initial nitrogen content can be explained thermodynamically as the equilibrium state is reached.

(3) The optimum size of ferrochrome is $1 \sim 5 \mathrm{mmo}$.

(4) In VIF, if a solid oxide is mixed with ferrochrome in granular form, the prevention of nitrogen absorption becomes possible owing to the decarburization during melting. The denitrided ferrochrome in granular form is suitable source of chromium for high purity stainless steel of extremely low nitrogen concentration.

\section{Introduction}

It is difficult to reduce the nitrogen content of highchrome stainless steels ( $\mathrm{Cr} \geqq 25 \%$ ) to $30 \mathrm{ppm}$ or less by any refining methods using normally available sources of chromium. $\left.{ }^{1-10}\right)$ In order to melt highchrome high-purity ferritic stainless steel (for example, a grade of $25 \% \mathrm{Cr}-4 \%$ Mo with maximal total carbon and nitrogen content of $50 \mathrm{ppm}$ ) in a vacuum induction furnace, a process has been studied to treat low carbon ferrochrome of very low nitrogen content and to use this denitrided ferrochrome as the source of chromium.
Treatment of ferrochrome in granular form with $\mathrm{Ca}-\mathrm{CaCl}_{2}$ or $\mathrm{Mg}-\mathrm{MgCl}_{2}$ flux is reported as the basic procedure for denitriding ferrochrome. ${ }^{11)}$ This paper describes the results of experiments conducted to put this basic procedure into practice and, especially, the effects of flux composition, quantity and temperature on the denitridation of ferrochrome. A study has also been made on the conditions of vacuum melting which permit an effective use of denitrided granular ferrochrome for melting of high-purity stainless steel.

\section{Experiment}

The entire denitriding process of ferrochrome is shown in Table 1. A commercial grade low-carbon ferrochrome which is mechanically crushed into granular form was used in the present experiment. Fluxes used were metallic magnesium and anhydrous chlorides (mainly $\mathrm{MgCl}_{2}$, and $\mathrm{CaCl}_{2}$ and $\mathrm{NaCl}$ for comparison). Compositions of the raw materials and the experimental conditions adopted are given in Tables 2 and 3.

About $30 \mathrm{Kg}$ of ferrochrome granules and flux were charged into a container made of stainless steel in the order of magnesium, ferrochrome granules and chloride layers. Then, the container was placed in a closed vessel as shown in Fig. 1. Heating was made in a low-frequency induction furnace. Argon was introduced to the vessel with the rate of about $50 \mathrm{l} / \mathrm{min}$ during the initial period and less than $2 \mathrm{l} / \mathrm{min}$ after

Table 1. Procedure of experiment

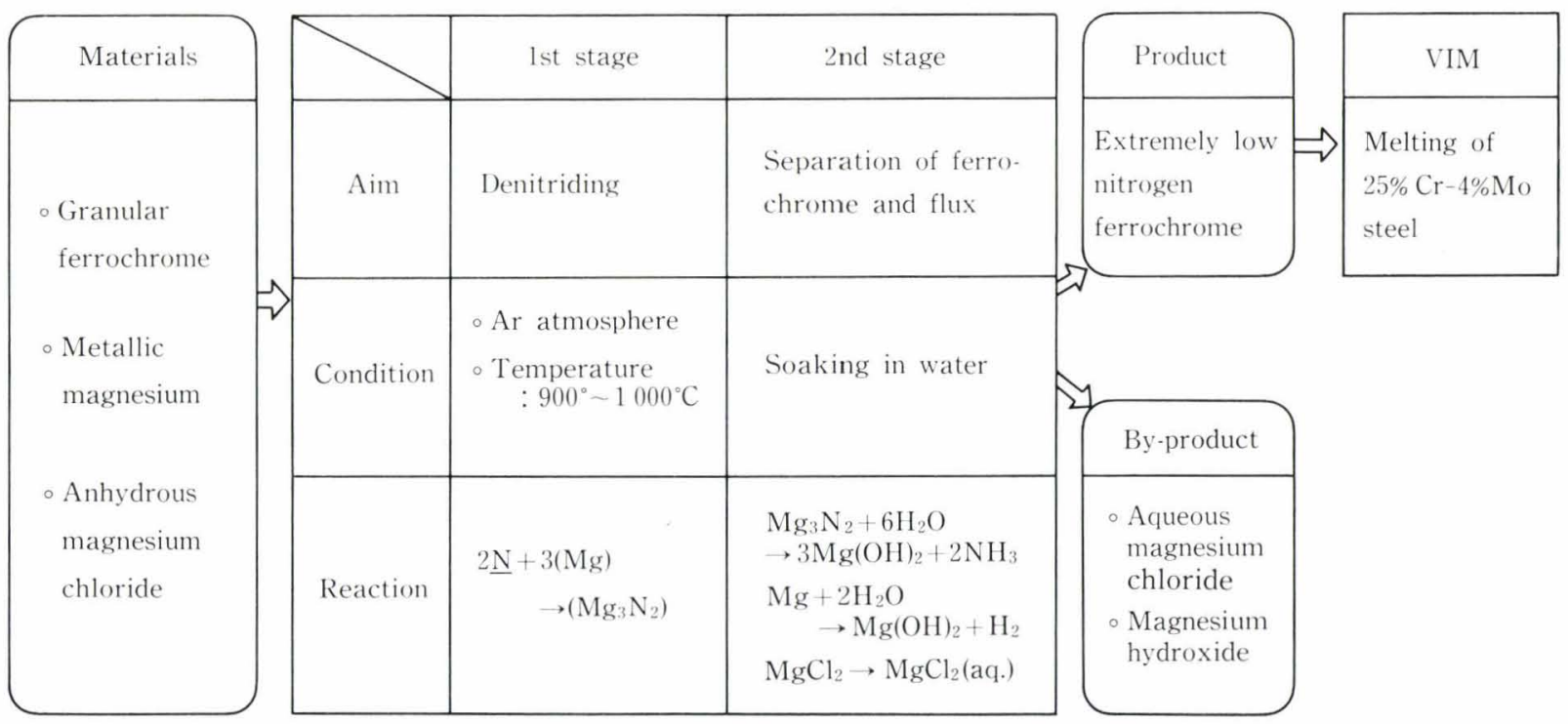

* Originally published in Tetsu-to-Hagané, 64 (1978), 2139, in Japanese. English version received December 8, 1978.

** Process Metallurgy Laboratories, Nippon Steel Corp., Edamitsu-cho, Yawata-ku, Kitakyushu 805.

*** Fundamental Research Laboratories, Nippon Steel Corp., Ida, Nakahara-ku, Kawasaki 229. 
Table 2. Experimental conditions

\begin{tabular}{|c|c|c|c|}
\hline & Item & \multicolumn{2}{|c|}{ Experimental condition } \\
\hline \multirow{3}{*}{ Materials } & \multirow{2}{*}{$\begin{array}{l}\text { Low carbon } \\
\text { ferrochrome }\end{array}$} & Size & $0.15 \sim 6.0 \mathrm{~mm} \dot{\phi}$ \\
\hline & & Initial N & $190 \sim 830 \mathrm{ppm}$ \\
\hline & $\begin{array}{l}\text { Anhydrous } \\
\text { chloride }\end{array}$ & \multicolumn{2}{|c|}{$\mathrm{MgCl}_{2}, \mathrm{CaCl}_{2}, \mathrm{NaCl}$} \\
\hline \multirow{5}{*}{ 1 st Stage } & Amount of & $\mathrm{Mg}$ & $\begin{array}{l}5 \sim 55 \mathrm{~kg} / \mathrm{t}- \\
\text { ferrochrome }\end{array}$ \\
\hline & & $\begin{array}{l}\text { Anhydrous } \\
\text { chloride }\end{array}$ & $\begin{array}{l}25 \sim 550 \mathrm{~kg} / \mathrm{t}- \\
\text { ferrochrome }\end{array}$ \\
\hline & $\begin{array}{l}\text { Addition to } \\
\text { flux }\end{array}$ & \multicolumn{2}{|c|}{$\mathrm{MgO}, \mathrm{CaF}_{2}, \mathrm{H}_{2} \mathrm{O}$} \\
\hline & Temperature & \multicolumn{2}{|c|}{$940^{\circ} \sim 1030^{\circ} \mathrm{C}$} \\
\hline & Holding time & \multicolumn{2}{|c|}{$60 \sim 300 \mathrm{~min}$} \\
\hline 2 nd Stage & $\begin{array}{l}\text { Temperature } \\
\text { of water }\end{array}$ & \multicolumn{2}{|c|}{$15^{\circ} \sim 20^{\circ} \mathrm{C}, 50^{\circ} \sim 70^{\circ} \mathrm{C}$} \\
\hline
\end{tabular}

Table 3. Chemical composition of materials

(a) Granular ferrochrome

\begin{tabular}{cccccccc}
\hline & $\begin{array}{c}\mathrm{Cr} \\
(\%)\end{array}$ & $\begin{array}{c}\mathrm{N} \\
(\mathrm{ppm})\end{array}$ & $\begin{array}{c}\mathrm{C} \\
(\%)\end{array}$ & $\begin{array}{c}\mathrm{Si} \\
(\%)\end{array}$ & $\begin{array}{c}\mathrm{S} \\
(\%)\end{array}$ & $\begin{array}{c}\mathrm{P} \\
(\%)\end{array}$ & $\begin{array}{c}\text { Total O } \\
(\%)\end{array}$ \\
\hline $\mathrm{A}$ & 61.0 & 190 & 0.009 & 0.75 & 0.007 & 0.020 & 0.12 \\
$\mathrm{~B}$ & 62.0 & 230 & 0.009 & 0.83 & 0.006 & 0.017 & 0.20 \\
$\mathrm{C}$ & 61.0 & 830 & 0.028 & 0.46 & 0.006 & 0.032 & 0.29 \\
\hline
\end{tabular}

(b) Metallic magnesium (\%)

\begin{tabular}{cccccc}
$\mathrm{Mg}$ & $\mathrm{Fe}$ & $\mathrm{Si}$ & $\mathrm{Zn}$ & $\mathrm{Mn}$ & $\mathrm{Al}$ \\
\hline$>99.90$ & $<0.01$ & $<0.01$ & $<0.05$ & $<0.01$ & $<0.01$
\end{tabular}

(c) Anhydrous chloride (\%)

\begin{tabular}{l|ccc} 
& Chloride & Free acid $(\mathrm{HCl})$ & $\mathrm{H}_{2} \mathrm{O}^{*}$ \\
\hline $\mathrm{MgCl}_{2}$ & $>99.0$ & & $<2$ \\
$\mathrm{CaCl}_{2}$ & $>95.0$ & 0.008 & $10 \sim 15$ \\
$\mathrm{NaCl}$ & $>95.5$ & $<0.004$ & $<2$
\end{tabular}

* assumed value from ignition loss

that period.

Temperatures were continuously measured with alumel-chromel thermocouples inserted to the hottest position of the vessel and to the center of the charge. The reaction temperature was kept constant by manually switching the current on and off. Temperature fluctuation was within $\pm 30^{\circ} \mathrm{C}$ and the average temperature difference of each position was within $\pm 20^{\circ} \mathrm{C}$. The charged materials were not stirred compulsorily.

After heating, the reaction product was cooled in the vessel to $200^{\circ} \mathrm{C}$ or lower and immersed in water to separate the ferrochrome in granular form from the flux (the second step in Table 1). The separated ferrochrome granules were washed, dried and analyzed for nitrogen in accordance with JIS G 1228. The analytical errors were within $\pm 5 \mathrm{ppm}$ (soluble nitrogen: within $\pm 2 \mathrm{ppm}$, and insoluble nitrogen: within $\pm 3 \mathrm{ppm})$.

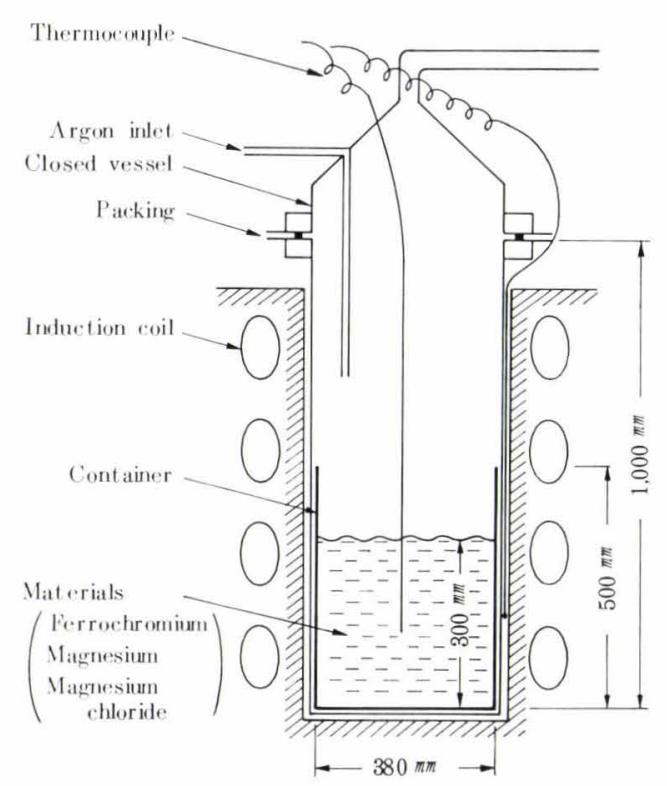

Fig. 1. Schematic drawing of the experiment of first stage

A vacuum induction furnace of $10 \mathrm{Kg}$ capacity was used to melt a $25 \% \mathrm{Cr}-4 \%$ Mo steel using denitrided ferrochrome granules as the source of chromium, electrolytic iron or rimming steel scrap as the source of iron, and metallic molybdenum as the source of molybdenum. As for the melting conditions, the pressure inside the vacuum furnace and the amount of iron oxide powder added as the source of oxygen were varied. Samples were taken from the molten steel with a quartz tube. Carbon was analyzed by the combustion infrared absorption method, and nitrogen by JIS G 1228 .

\section{Experimental Results}

\section{Denitriding of Ferrochrome Granules}

Figure 2 shows the nitrogen content of ferrochrome in each position of the container. Nitrogen contents are almost the same, except those at the surface layer. The nitrogen content of each heat is expressed by the average of the analytical values of three or more samples taken after mixing.

Figure 3 shows the nitrogen content of denitrided ferrochrome granules screened and classified by the particle size. When the reaction time is short, the greater the particle diameter is, the higher the nitrogen content tends to become. But if the ferrochrome is held at $970^{\circ} \mathrm{C}$ for $2.8 \mathrm{hr}$, for example, the nitrogen content remains practically the same up to the particle diameter of $6 \mathrm{~mm}$. Incidentally, it seems strange that the nitrogen content increases at the particle diameter of less than $0.3 \mathrm{~mm}$. This is not because the denitridation did not progress but because the separation of flux was not complete enough. ${ }^{11)}$ The rate-determining step for the denitriding reaction is considered to be nitrogen diffusion in the ferrochrome granule. When the nitrogen content after denitridation does not depend on the diameter of ferrochrome granules, the reaction is considered to have reached an apparent equilibrium. Almost all the experiments were done 


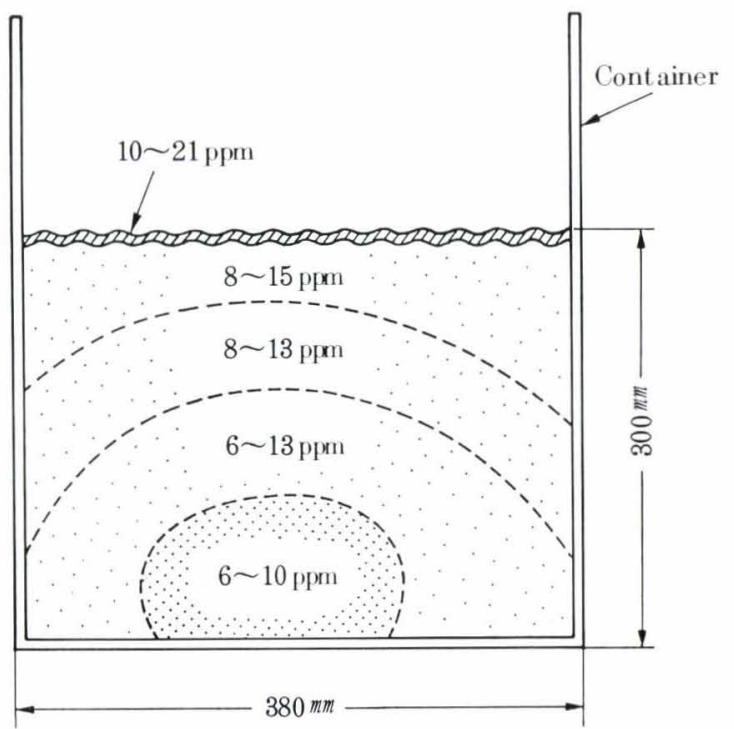

$$
\begin{aligned}
\text { Initial } \mathrm{N}: & 230 \mathrm{ppm} \\
\mathrm{MgCl}_{2}: & 200 \mathrm{~kg} / t \\
\mathrm{Mg}: & 20 \mathrm{~kg} / t \\
\text { Temp.: } & 980^{\circ} \mathrm{C}
\end{aligned}
$$

Fig. 2. Distribution of the nitrogen content of ferrochrome in the container
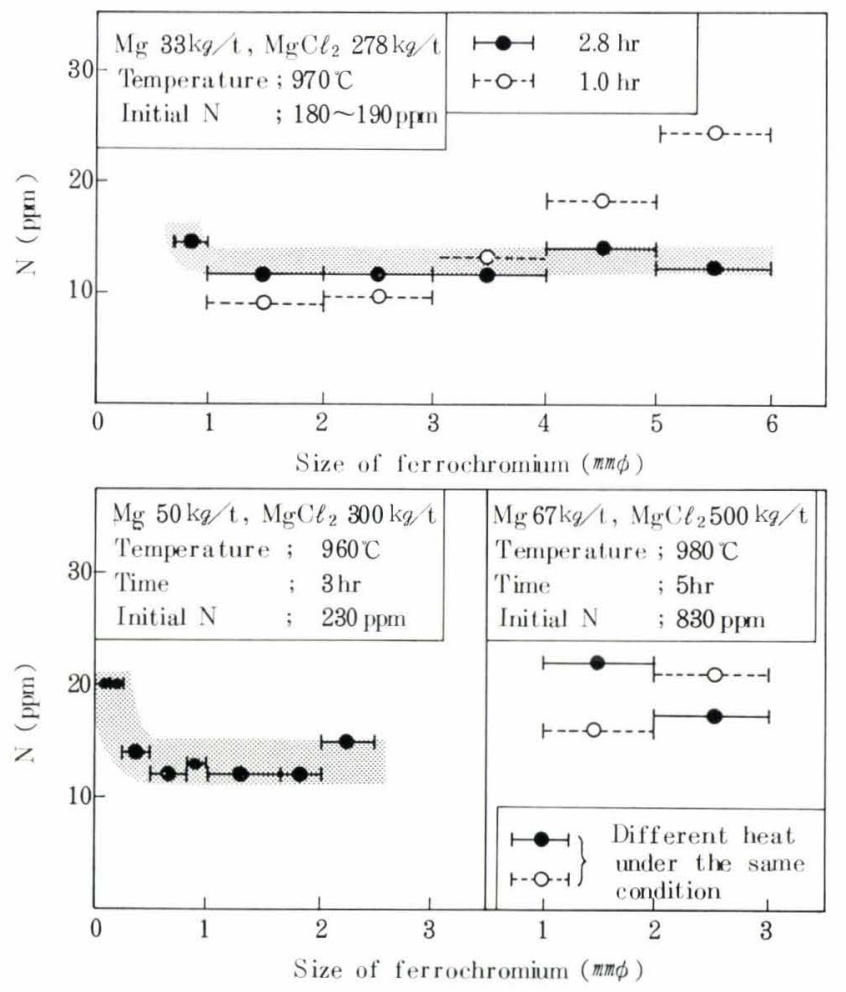

Fig. 3. Influence of the size of ferrochrome on the nitrogen content after denitriding

under the condition that the nitrogen content after the denitriding process is not affected by the size of ferrochrome particle.

Figure 4 shows the influence of the addition of flux. The greater the addition of $\mathrm{MgCl}_{2}$ is, the lower the nitrogen content becomes. On the other hand, magnesium has no effect on the nitrogen content even
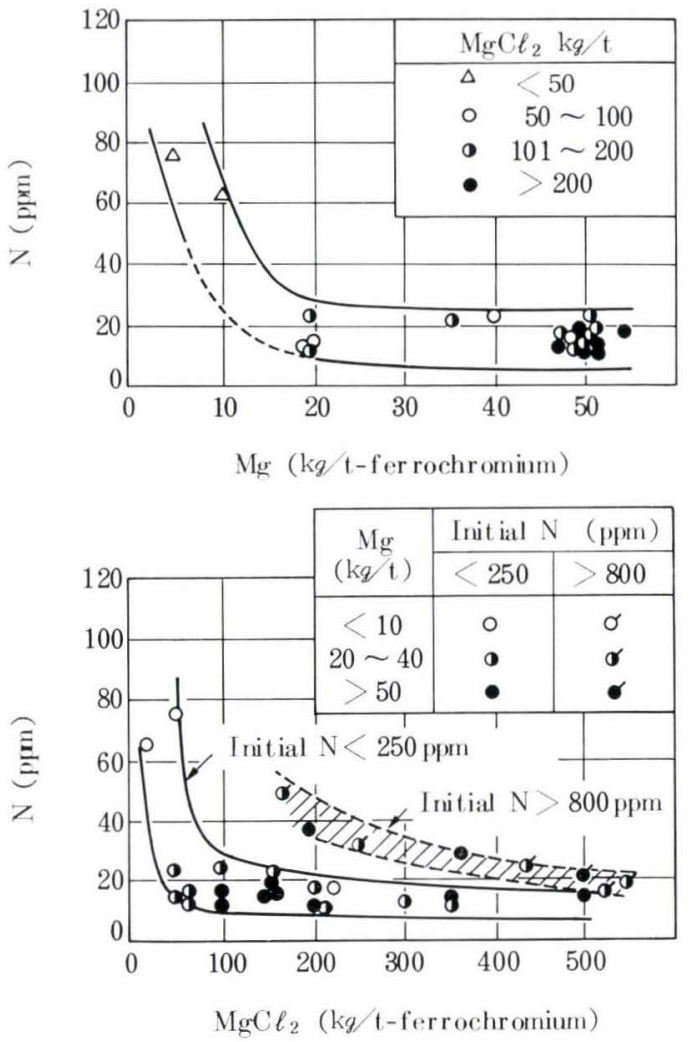

Temp.: $960^{\circ}$ to $980^{\circ} \mathrm{C}$

Fig. 4. Influence of the amount of $\mathrm{Mg}$ and $\mathrm{MgCl}_{2}$ on the nitrogen content of ferrochrome after denitriding

by the addition of more than $20 \mathrm{~kg} / \mathrm{t}$.

As the anhydrous chloride is hygroscopic, it was afraid that its variation in water content would make the denitriding reaction unstable. This is because the water evaporates on heating and oxidizes the magnesium and ferrochrome granules, and the resultant $\mathrm{MgO}$ may adversely affect the progress of denitridation. Therefore, the experiment was carried out to intentionally add $\mathrm{MgO}$ and water to the flux.

No difference in the nitrogen content was recognized when about $20 \% \mathrm{MgO}$ was added to the flux (Fig. 5 (b)). And, as shown in Fig. 5 (c), the nitrogen content also drops to the same level if the amount of magnesium is increased in accordance with the amount of water added. This shows that the problem of hygroscopicity of anhydrous chlorides, only the unstable factor in this treatment, can be solved by the addition of magnesium in an optimum quantity. But it is desirable to use anhydrous chloride of as low as possible water content for suppressing the generation of hydrochloric acid on heating (Eqs. (1) and (2)), which is apt to corrode the container.

$$
\begin{aligned}
\mathrm{MgCl}_{2} \cdot 6 \mathrm{H}_{2} \mathrm{O} & \longrightarrow \mathrm{Mg}(\mathrm{OH}) \mathrm{Cl}+\mathrm{HCl}+5 \mathrm{H}_{2} \mathrm{O} \ldots \\
\mathrm{Mg}(\mathrm{OH}) \mathrm{Cl} & \longrightarrow \mathrm{MgO}+\mathrm{HCl} \ldots \ldots \ldots \ldots \ldots \ldots \ldots
\end{aligned}
$$

Figure 6 shows the effect of temperature on the denitridation. The holding time at each reaction temperature is so selected that the reaction reaches an apparent equilibrium ( 1 to $3 \mathrm{hr}$ at $970^{\circ} \mathrm{C}$ or more: 4 to $6 \mathrm{hr}$ at $950^{\circ}$ to $960^{\circ} \mathrm{C}$ : and $10 \mathrm{hr}$ at $940^{\circ} \mathrm{C}$ or less). 


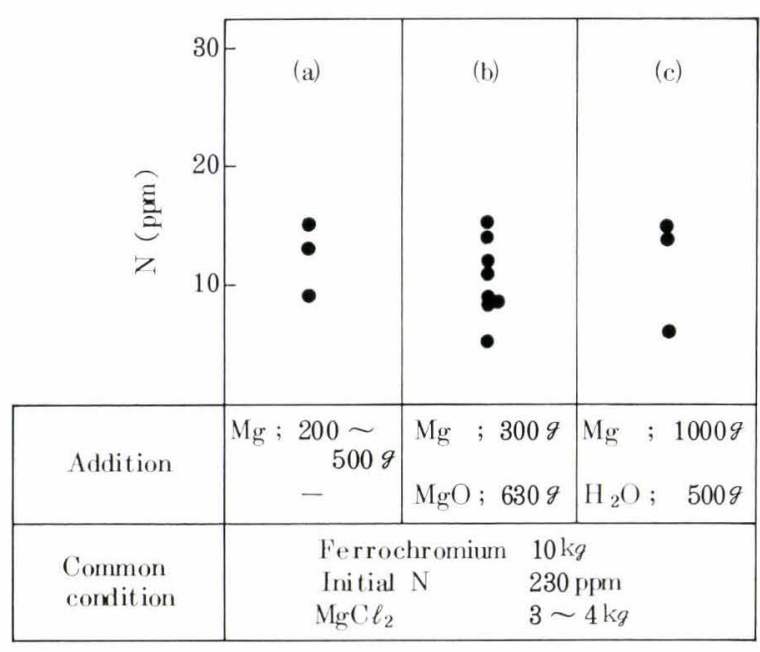

Fig. 5. Influence of addition to flux on the nitrogen content of ferrochrome after denitriding

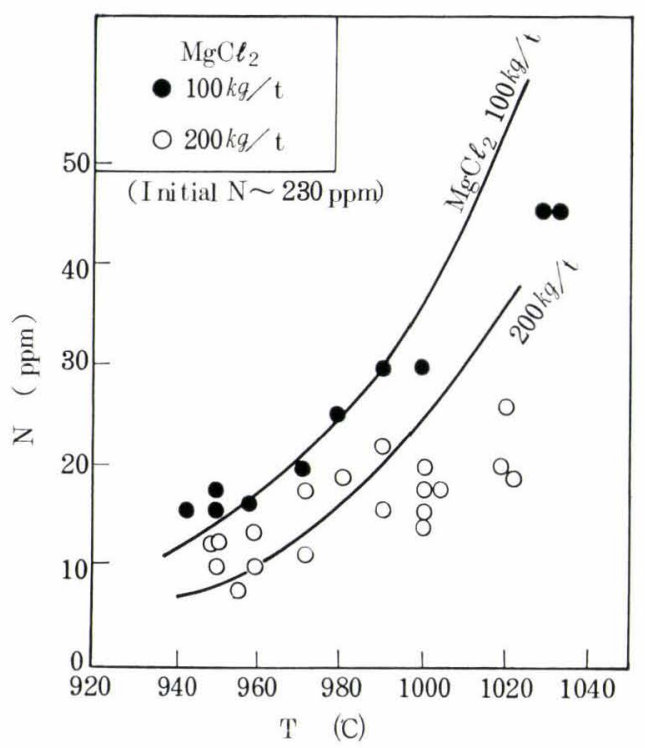

Solid line: calculated from Eq. (12)

Fig. 6. Influence of temperature on the nitrogen content of ferrochrome after denitridiing

Under the same flux conditions, the lower the reaction temperature is, the lower the nitrogen content after denitriding becomes.

Figure 7 shows the results obtained with $\mathrm{CaCl}_{2}$ or $\mathrm{NaCl}$ instead of $\mathrm{MgCl}_{2}$. There are large variations in the nitrogen content after denitridation with $\mathrm{Mg}$ $\mathrm{CaCl}_{2}$ flux. One of the reasons is that the $\mathrm{CaCl}_{2}$ used had a high water content (Table. 3). An increased addition of magnesium provides the denitriding like that obtained with $\mathrm{Mg}-\mathrm{MgCl}_{2}$ flux. Although a part of denitriding reaction initiates at $930^{\circ} \mathrm{C}$ by the use of $\mathrm{Mg}-\mathrm{NaCl}$ flux (the holding time is $4 \mathrm{hr}$ in this case and an apparent equilibrium is probably not reached), the degree of denitriding at $980^{\circ} \mathrm{C}$ is extremely low. In the latter case, the reaction in Eq. (3) seems to proceed and to consume magnesium in the flux.

$$
\mathrm{Mg}+2 \mathrm{NaCl} \longrightarrow \mathrm{MgCl}_{2}+2 \mathrm{Na}
$$

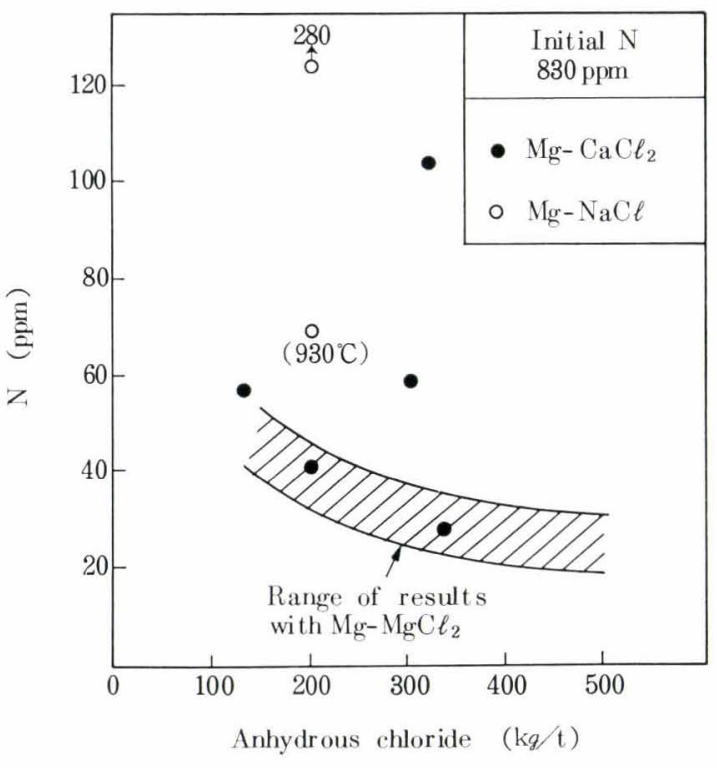

Temp.: $960^{\circ}$ to $980^{\circ} \mathrm{C}$ except the heat shown in ( )

Fig. 7. Results of denitriding with different fluxes

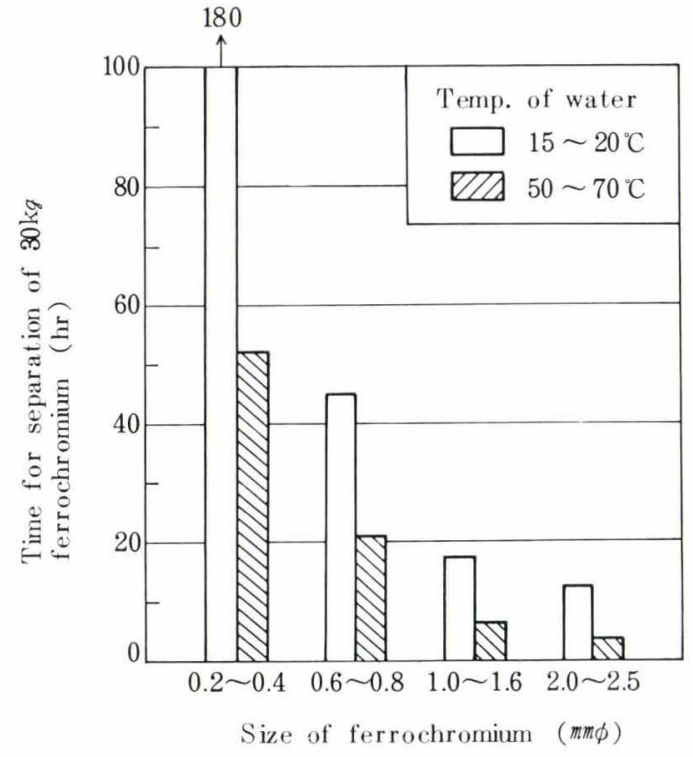

Fig. 8. Influence of the size of ferrochrome and temperature of water on the time required for separation of ferrochrome and flux

\section{Separation of Ferrochrome Granules and Flux}

Figure 8 shows the time required to separate ferrochrome from the flux by immersing about $30 \mathrm{Kg}$ of lumpy material obtained in the second step of this experiment in water. The time required is affected by the particle size of ferrochrome and the temperature of water. The greater the particle size of ferrochrome is, the more readily the water will permeate and the separation of ferrochrome will be accelerated.

Almost all the gases generated in this step is $\mathrm{H}_{2}$. The nitrogen fixed in the flux forms $\mathrm{NH}_{3}$, which is readily absorbed by water. Generation of gases which are objectionable in terms of the working environment, such as $\mathrm{PH}_{3}$, may be prevented if the range of 


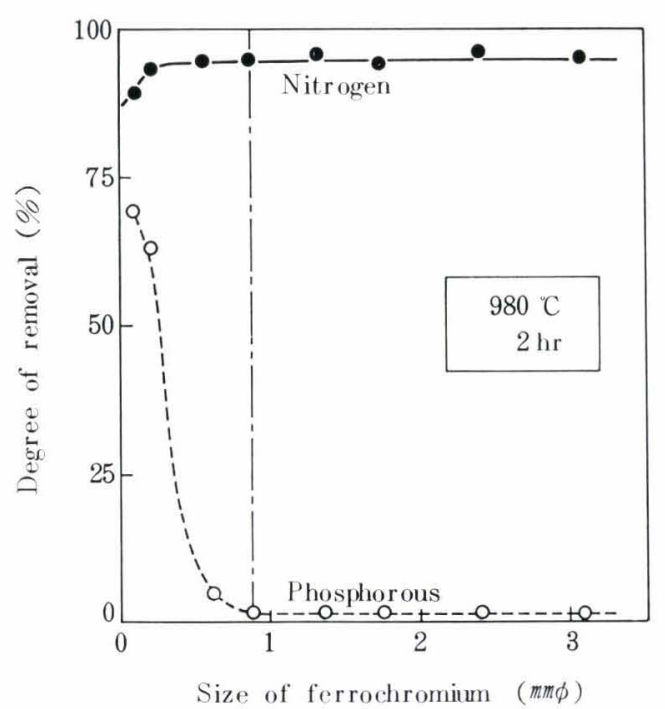

Fig. 9. Influence of the size of ferrochrome on the nitrogen and phosphorous removal

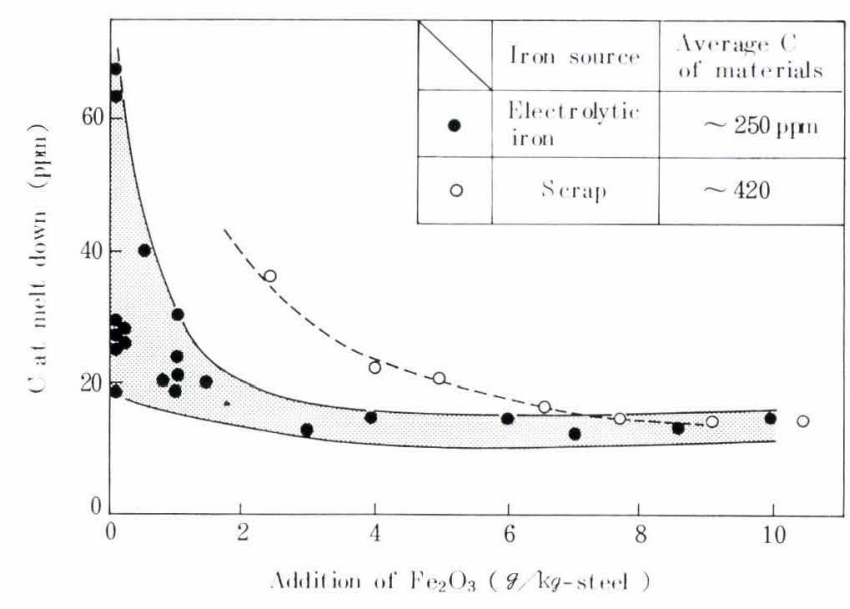

Fig. 10. Influence of the addition of $\mathrm{Fe}_{2} \mathrm{O}_{3}$ on carbon content of $25 \% \mathrm{Cr}-4 \% \mathrm{Mo}$ steel at meltdown

ferrochrome particle size is selected previously so as to preclude the dephosporization as shown in Fig. 9.

\section{Melting of High-purity Stainless Steel with Denitrided Ferrochrome in Vacuum Induction Furnace}

To make an effective use of denitrided ferrochrome granules for melting of high-purity stainless steel, it is important to find out the conditions which prevent the absorption of nitrogen and facilitate the decarburization during melting.

The carbon content at the time of melt down is between 25 and $70 \mathrm{ppm}$, even when electrolytic iron of low carbon content which is very expensive is used as the source of iron. In this case, the decarburization is necessary after melt down. The time required for the decarburization would be long in a large furnace (e.g. over $2 \mathrm{hr}$ for a $5 \mathrm{t} /$ heat). Moreover, nitrogen of 10 to $30 \mathrm{ppm}$ above the average nitrogen content of raw materials is absorbed when the pressure is $10^{-3}$ torr or higher. On the other hand, the evaporation loss of chromium becomes conspicuous when the pressure drops below $10^{-3}$ torr.

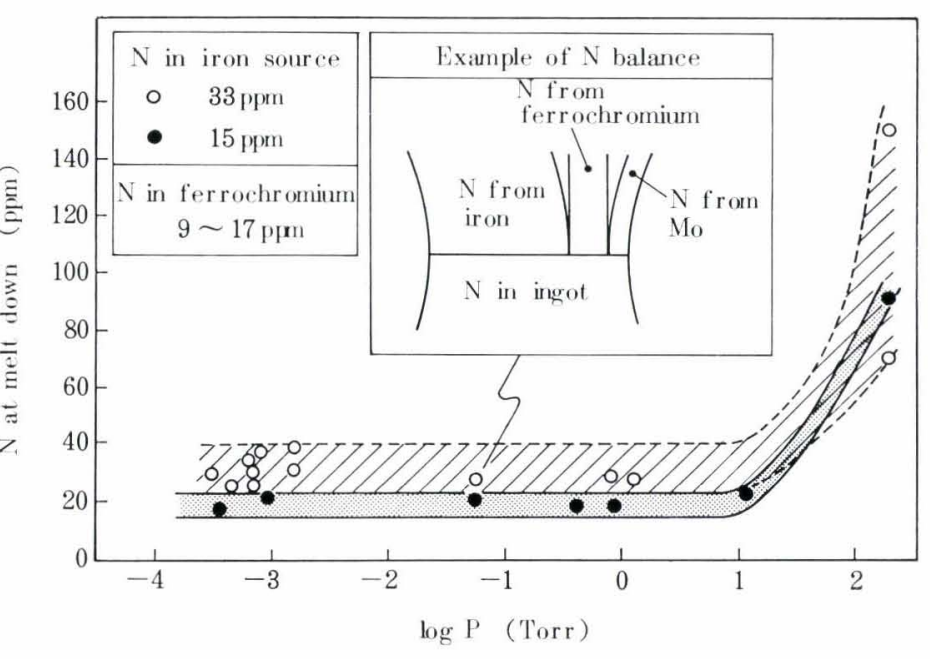

Fig. 11. Influence of the pressure on the nitrogen content of $25 \% \mathrm{Cr}-4 \%$ Mo steel at meltdown

To make lower the carbon content at the time of melt down, iron oxide powder was mixed in the charge for melting of $25 \% \mathrm{Cr}-4 \% \mathrm{Mo}$ steel. Figure 10 shows the effect of the amount of iron oxide added on the carbon content at the time of melt down. If iron oxide of more than $6 \mathrm{~g} / \mathrm{Kg}$-steel is mixed, the carbon content at the time of melt down can be stably reduced to $20 \mathrm{ppm}$ or less even when the average carbon content of raw materials is 420 ppm (rimming-steel scrap is used as the source of iron). When the steel is heated above $1650^{\circ} \mathrm{C}$ after melt down, most of the oxides are reduced by carbon and do not remain in the steel. Thus, there is virtually no oxidation loss of chromium and, hence, no problems for tapping and ingotmaking.

Figure 11 shows the relationship between the pressure and the nitrogen content at the time of melt down when the steel is melted with iron oxide added. No effect is recognized at the pressure of 10 torr and below. When the nitrogen balance in this region is taken, the nitrogen content at the time of melt down virtually coincides with the average nitrogen content of the charge. This shows that no nitrogen absorption occurs during melting. Without resorting to such a low pressure, the absorption of nitrogen was prevented due probably to the fact that the generation of $\mathrm{CO}$ gas accompanied by the decarburization lowered $P_{\mathrm{N}_{2}}$ near the melt.

As mentioned above, if iron oxide is mixed in the charge by applying the shape characteristic of granular ferrochrome, the decarburization to extremely low carbon concentration and the suppression of nitrogen pick up can be achieved at the same time. Therefore, denitrided ferrochrome of glanular form is thought to be a suitable material for melting of extremely low carbon and nitrogen stainless steels.

\section{Discussion}

\section{Chemical Aspect of Denitridation}

Figure 12 shows the relationship between the freeenergy change of formation $\left(\Delta \mathrm{G}_{f}^{\circ}\right)$ and the temperatures of magnesium and calcium compounds. ${ }^{12)}$ The 


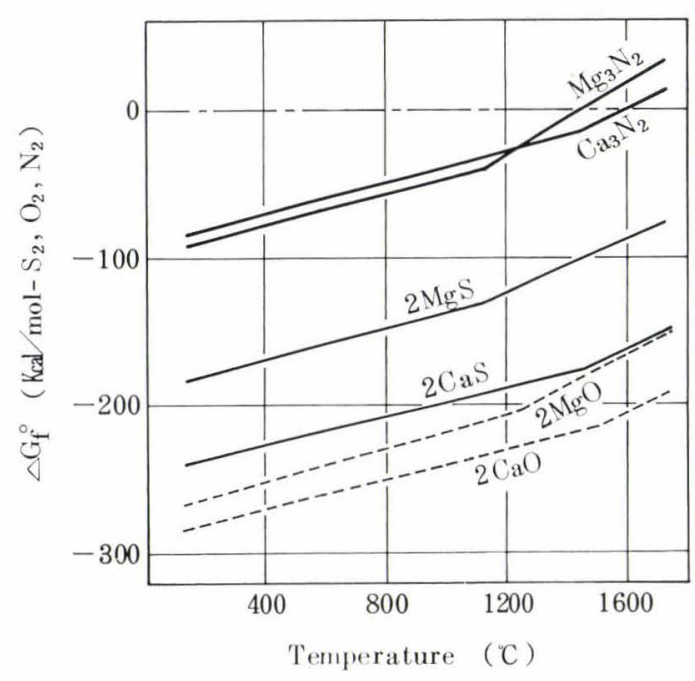

Fig. 12. Influence of temperature on $\Delta \mathrm{G}^{\circ}$ of various compounds of calcium and magnesium

values of $\left|\Delta \mathrm{G}_{f}^{\circ}\right|$ for nitrides are smaller than those for oxides and sulphide. Denitridation in the molten state (over $1600^{\circ} \mathrm{C}$ ) is impossible thermodynamically. Although magnesium and calcium are almost equal to each other in the values of $\left|\Delta \mathrm{G}^{\circ}{ }_{f}\right|$ at temperatures below $1100^{\circ} \mathrm{C}$, the value of $\left|\Delta \mathrm{G}^{\circ}{ }_{f}\right|$ for magnesium becomes suddenly smaller when the temperature exceeds $1100^{\circ} \mathrm{C}$. Furthermore, since the vapor pressure of magnesium is higher than that of calcium, for the effective denitridation with magnesium, the denitriding temperature must be selected as low as possible by considering the particle size and holding time.

The Equations for the denitridation can be expressed as follow:

$$
\begin{aligned}
& 3(\mathrm{Mg})+2[\mathrm{~N}]=\left(\mathrm{Mg}_{3} \mathrm{~N}_{2}\right) \\
& K=\frac{\left(a_{\mathrm{Mg}_{3} \mathrm{~N}_{2}}\right)}{\left(a_{\mathrm{Mg}}\right)^{3} \cdot\left(a_{\mathrm{N}}\right)^{2}}=e^{-}
\end{aligned}
$$

where $a_{\mathrm{Mg}_{3} \mathrm{~N}_{2}}$ and $a_{\mathrm{Mg}}$ are the activities of $\mathrm{Mg}_{3} \mathrm{~N}_{2}$ and $\mathrm{Mg}$, respectively, and $a_{\mathrm{N}}$ the activity of nitrogen in ferrochrome. By the X-ray diffraction of lumpy matter obtained at the end of the first step, it was confirmed that nitrogen in the flux exists in the form of $\mathrm{Mg}_{3} \mathrm{~N}_{2}$, at least after solidification.

The value of $\Delta \mathrm{G}^{\circ}{ }_{(4)}$ at each temperature can be expressed by Eq. (6), using $\Delta \mathrm{G}^{\circ}{ }_{f}$ shown in Fig. 12 and $\Delta \mathrm{G}^{\circ}{ }_{(8)}$ defined by Eq. (7).

$$
\begin{gathered}
\Delta \mathrm{G}_{(4)}^{\circ}=\Delta \mathrm{G}_{\mathrm{f}}^{\circ}-\Delta \mathrm{G}_{(8)}^{\circ} \ldots \\
\Delta \mathrm{G}_{(8)}^{\circ}=13448+11.0 \mathrm{~T}
\end{gathered}
$$

$\Delta \mathrm{G}^{\circ}{ }_{(8)}$ the standard free-energy change of Eq. (8)

$$
\mathrm{N}_{2}(\mathrm{~g})=2[\mathcal{N}] \quad(1 \% \text { in } \alpha \text {-iron })
$$

is calculated by extrapolating the data of the solubility of nitrogen in $\alpha$-iron ${ }^{13)}$ in the temperature range from $900^{\circ}$ to $1050^{\circ} \mathrm{C}$, because the phase of $\mathrm{Fe}-\mathrm{Cr}(\sim 60 \%)$ is $\alpha$ at the experimental temperature.

The relationship shown in Fig. 13 (a) may be valid for the value of $a_{\mathrm{Mg}}$ and the residual magnesium in the flux. The point $S_{\mathrm{M}}$ in the figure exhibits the solubility of magnesium in the flux. It is reported that the

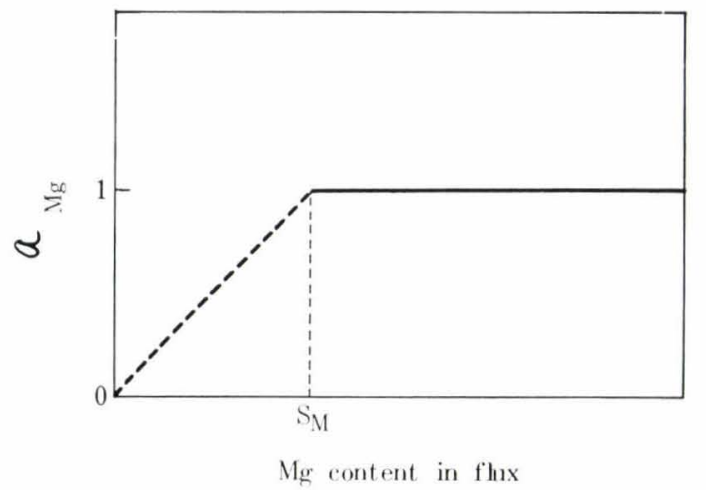

Fig. 13 (a) Assumed relationship between activity of magnesium and magnesium content in flux

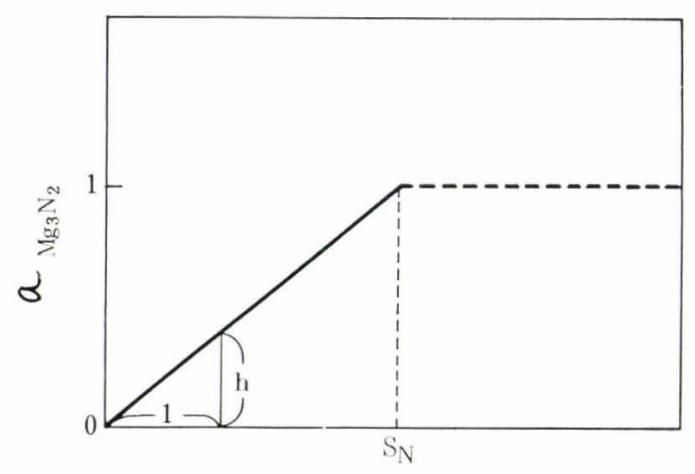

Total nitrogen content in flux

Fig. 13 (b) Assumed relationship between activity of magnesium nitride and nitrogen content in flux

solubility of magnesium is $0.7 \mathrm{~mol} \%$ for $\mathrm{Mg}-\mathrm{MaCl}_{2}$ flux at $1000^{\circ} \mathrm{C}$ and $0.05 \mathrm{~mol} \%$ for $\mathrm{Mg}-\mathrm{CaCl}_{2}$ flux at $1100^{\circ} \mathrm{C}^{14)}$ According to the chemical analyses of the flux at the end of the first step or this experiment, the magnesium content was ranging from 0.5 to $22.5 \%$. Moreover the existence of magnesium particles was observed macroscopically in the lump obtained at the end of the first step. Thus, the following relation may be satisfied.

$$
a_{\mathrm{Mg}}=1
$$

Then, the following Equation is obtained.

$$
a_{N}=f_{N} \cdot 10^{-4}
$$

where $f_{N}$ is the accivity coefficient of nitrogen in ferrochromium and $10^{-4}$ is the conversion factor of percentage into ppm.

A relationship shown in Fig. 13 (b) may be valid for the value of $a_{\mathrm{Mg}_{3} \mathrm{~N}_{2}}$ and the total nitrogen content of the flux. Although there are no available reports, the point $S_{N}$ (the solubility of nitrogen in the flux) may be considered to fall on the solid line in Fig 13(b) because the nitrogen content of the flux was low under the present experimental conditions. If the slope of the solid line is expressed by $h$, the following Equations are valid:

$$
\begin{aligned}
& a_{\mathrm{Mg}_{3} \mathrm{~N}_{2}}=h \cdot(\mathcal{N}(\%) \text { in flux }) \\
& \approx \frac{h}{10} \frac{[\text { initial } \mathcal{N}(\mathrm{ppm})]-[\text { final } \mathcal{N}(\mathrm{ppm})]}{[\text { amount of flux }(\mathrm{kg} / t)]}
\end{aligned}
$$




$$
\approx \frac{h}{10} \frac{[\text { initial } \mathcal{N}(\mathrm{ppm})]}{[\text { amount of chloride }(\mathrm{kg} / t)]}
$$

Substituting Eqs. (9) and (12) in Eq. (5) and rearranging the Equation, it becomes as follows:

$$
\begin{aligned}
& \text { [final } \mathcal{N}(\mathrm{ppm})]^{2} \\
& \qquad \frac{10^{7}}{K^{\prime}} \cdot \frac{[\text { initial } \mathcal{N}(\mathrm{ppm})]}{[\text { amount of chloride }(\mathrm{kg} / t)]}
\end{aligned}
$$

where,

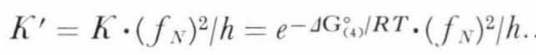

If $K^{\prime}=3.08 \times 10^{4}(\mathrm{ppm} \cdot \mathrm{kg} / t)$, the results of calculation by Eq. (13) become to be approximately equal to the experimental results obtained at $960^{\circ}$ to $980^{\circ} \mathrm{C}$ (Fig. 14).

As for the influence of reaction temperature, $K^{\prime}$ is obtained from $K$ at each temperature by assuming $\left(f_{N}\right)^{2} / h$ is constant $\left(3.20 \times 10^{-7}\right)$ and the results of calculation by Eq. (13) are given in Fig. 6. In the temperature range of higher than $1000^{\circ} \mathrm{C}$, nitrogen contents gained in experiments are lower than calculated values. It seems to be one of the reasons of the deviation that additive denitration would proceed during cooling.

\section{Physical Aspect of Denitriding}

It is practically very difficult to stir compulsorily the ferrochrome granules and flux in the first step of this experiment. A cold model experiment was conducted to estimate the amount of flux required for uniform denitridation, without forced stirring. At first, a certain amount of ferrochrome screened and classified by the particle size was immersed in water. Then the container was tilted to let water flow out and the amount of water adhered to the ferrochrome glanules was determined (Fig. 15).

In the first step of this experiment, the anhydrous chloride was charged onto the layer of ferrochrome.

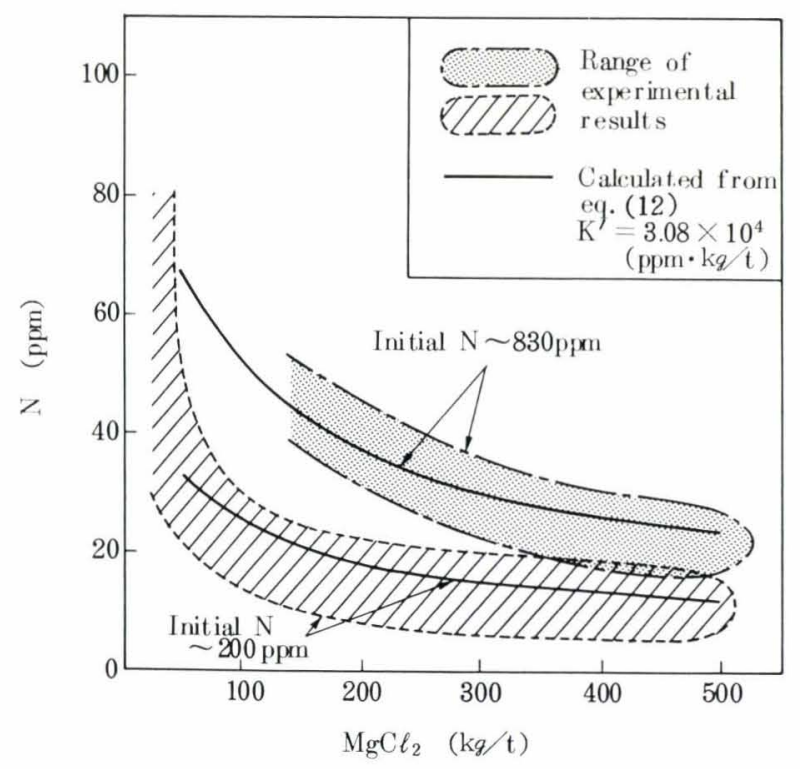

Fig. 14. Comparison of calculated value from Eq. (13) with experimental results (Temp.: $960^{\circ}$ to $980^{\circ} \mathrm{C}$ )
On heating the molten chloride is considered to drip while wetting the layer of ferrochrome from top to bottom. Therefore, the amount of flux required to wet the entire layer of ferrochrome approximately corresponds to the amount of water adhered and remaining in the layer of ferrochrome. If the kind of the liquid changes from water to molten flux, the amount of liquid adhered is considered to depend on the relationship between the surface tension $\left(\gamma_{l}\right)$ and the contact angle $(\theta)$ according to Eq. (14). ${ }^{15)}$

(The amount of liquid adhered $) \propto \gamma_{l}(1+\cos \theta) \ldots$

The surface tension $\gamma_{l}$ is about $72 \mathrm{dyn} / \mathrm{cm}$ for water and 80 to $180 \mathrm{dyn} / \mathrm{cm}$ for molten chlorides $\left(\mathrm{NaCl}_{2}\right.$, $\mathrm{KCl}, \mathrm{BaCl}_{2}$, RbCl and $\left.\mathrm{CsCl}\right) .{ }^{16)}$ No measurements on the contact angle to meet the present conditions are reported, but the contact angles both for water and flux are considered to be $30^{\circ}$ or less, so the difference in $(1+\cos \theta)$ between these two is thought to be not so large. Therefore, the amount of $\mathrm{Mg}-\mathrm{MgCl}_{2}$ flux adhered to ferrochrome granules is estimated to be about twice the amount of water or about $80 \mathrm{~kg} / t$, when the diameter of ferrochrome granules is 1 to $5 \mathrm{~mm}$. When the chloride was added $50 \mathrm{~kg} / t$ or less, the average nitrogen content after denitridation was high (Fig. 4), probably because of uneven permeation of the flux. Thus, the limit of the flux amount estimated by the above method is nearly the same as encountered in practice.

At the reaction temperature, it is estimated that the evaporation, condensation and dripping of the flux are repeated in accordance with the temperature distribution through the layer of ferrochrome. This seems helpful to the uniform progress of denitridation in respective positions without stirring.

\section{Summary}

(1) Treatment of ferrochrome in granular form

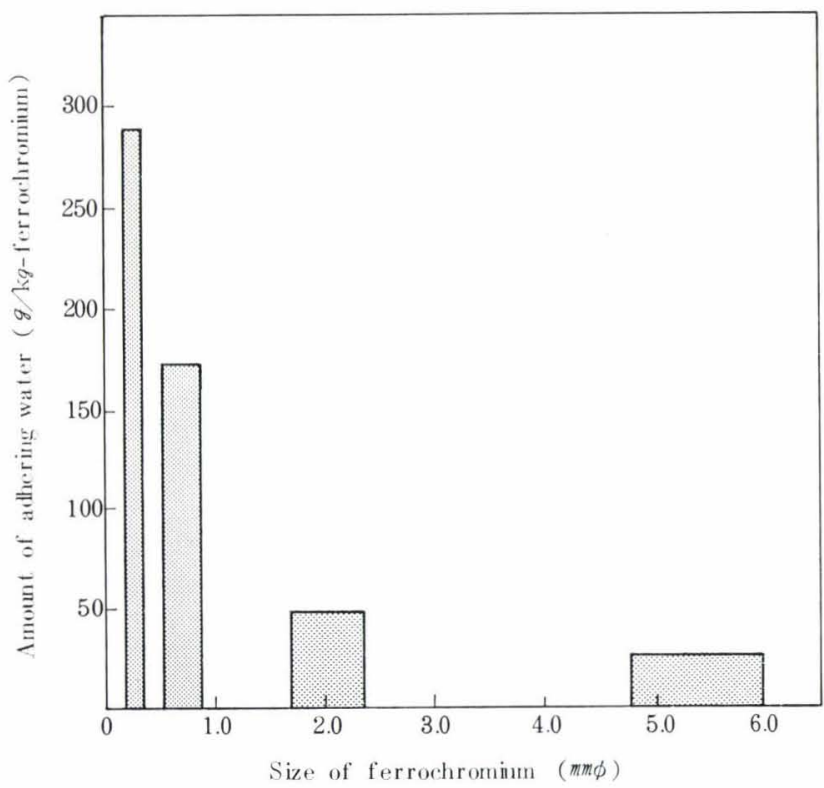

Fig. 15. Relationship between the size of ferrochrome and the amount of adhering water 
with $\mathrm{Mg}-\mathrm{MgCl}_{2}$ flux allows the denitridation to 20 ppm or less (minimum of 5 ppm).

(2) The optimum diameter of ferrochrome particle is 1 to $5 \mathrm{~mm}$.

(3) The amount of magnesium required to be added as the flux depends on the water content of raw materials, but $20 \mathrm{~kg} / t$ suffices for normal cases.

(4) The minimum amount of chloride for uniform reaction without compulsory stirring is about $80 \mathrm{~kg} / t$.

(5) The influence of the initial nitrogen content, temperature and the amount of flux can be explained thermodynamically, under the condition when the nitrogen content after denitridation is not affected by the diameter of ferrochrome particle.

(6) For melting of extremely low carbon and nitrogen stainless steel using denitrided ferrochrome granules, it is effective to mix iron oxide in the charging materials. In this condition, it is possible to make the content of carbon less than 20 ppm at the time of melt down and prevent the absorption of nitrogen. Therefore, ferritic stainless steels with a total carbon and nitrogen content of $50 \mathrm{ppm}$ or less can be stably melted.

(7) This process differs from other processes in respect that the greater the chromium content is, the lower the nitrogen content becomes. Thus, the process is suited for producing high chrome stainless steels or chrome-based alloys.

\section{REFERENCES}

1) T. H. Harrington and P. B. Palmer: Electric Furnace Proc.,
28 (1970), 34.

2) K. Kaneko, N. Sano and Y. Matsushita: Tetsu-to-Hagané, 62 (1976), 43.

3) H. Tezuka and M. Fujine: Tetsu-to-Hagané, 61 (1975), S537.

4) S. Maruhashi and T. Kuwano: Nisshin Steel Technical Report, (1970), No. 27, 1.

5) H. Katayama, H. Kajioka, M. Inotomi, F. Tanaka and H. Hosoda: Trans. ISIJ, 18 (1978), 761.

6) S. Iwaoka, T. Otani, H. Habu, A. Ejima, Y. Oguchi and S. Yano: Tetsu-to-Hagané, 63 (1977), Al.

7) M. Kawabata: Tetsu-to-Hagané, 50 (1964), 70.

8) A. E. Kogan and A. M. Levin: Steel in USSR, (1973), No 4, 300 .

9) R. M. Visokey, G. P. Bernsmann and A. McLean: Met. Trans., 3 (1972), 1163.

10) A. G. Ivanov, A. G. Schalimov and G. N. Okorokov: $I z v$. Akad. Nauk SSSR, Metally, (1970), No. 2, 96.

11) Y. Nakamura, M. Itoh and M. Uchimura: Trans. ISIJ, 18 (1978), 768.

12) J. F. Elliott, M. Gleiser and V. Ranakrishna: Thermochemistry for Steelmaking, I, Addison-Wesley Publishing Co., Mass., (1963), 258.

13) L. S. Darken and R. W. Gurry: Physical Chemistry of Metals, McGraw Hill Book Co., New York, (1953), 377.

14) P. S. Roges, J. W. Tomlinson and F. D. Richardson: Proc. Intern. Symp. on Phys. Chem. of Process Metallurgy, Pittsburgh, (1959), 909.

15) Chemistry of the Interface, Series of Experimental Chemistry, No. 7, ed. by Chemical Institute of Japan, Maruzen, Tokyo, (1956), 61 .

16) Chemical Handbook, Basic II, ed. by Chemical Institute of Japan, Maruzen, Tokyo, (1975), 607. 